\title{
Intramolecular Oxyl Radical Coupling Promotes O-O Bond Formation in a Homogeneous Mononuclear Mn-based Water Oxidation Catalyst: A Computational Mechanistic Investigation
}

\author{
Douglas W. Crandell, ${ }^{\dagger}$ Song Xu, ${ }^{\dagger}$ Jeremy M. Smith, ${ }^{\dagger}{ }^{*}$ and Mu-Hyun Baik ${ }^{\dagger, \dagger, \beta, *}$ \\ ${ }^{\dagger}$ Department of Chemistry, Indiana University, 800 E. Kirkwood Avenue, \\ Bloomington, IN 47405, USA; \\ Institute for Basic Science (IBS), Center for Catalytic Hydrocarbon Functionalization, Daejeon, \\ 305-701, South Korea \\ ${ }^{\S}$ Department of Chemistry, Korea Advanced Institute of Science and Technology (KAIST), \\ Daejeon, 305-701, South Korea
}

e-mail: $\underline{\text { smith962@indiana.edu; mbaik2805@kaist.ac.kr }}$

\begin{abstract}
The mechanism of water oxidation performed by a recently discovered manganese pyridinophane catalyst $\left[\mathrm{Mn}\left(\mathrm{Py}_{2} \mathrm{~N} t \mathrm{Bu}_{2}\right)\left(\mathrm{H}_{2} \mathrm{O}\right)_{2}\right]^{2+}$ is studied using density functional theory methods. A complete catalytic cycle is constructed and the catalytically active species is identified to consist of a $\mathrm{Mn}^{\mathrm{V}}$-bis(oxo) moiety that is generated from the resting state by a series of proton-coupled electron transfer reactions. Whereas the electronic ground state of this key intermediate is found to be a triplet, the most favorable pathway for $\mathrm{O}-\mathrm{O}$ bond formation is found on the quintet potential energy surface and involves an intramolecular coupling of two oxyl radicals with opposite spins bound to the Mn-center that adopts an electronic structure most consistent formally with a high-spin $\mathrm{Mn}^{\mathrm{III}}$ ion. Therefore, the thermally accessible high-spin quintet state that constitutes a typical and innate property of a first-row transition metal center plays a critical role for catalysis. It enables facile electron transfer between the oxo moieties and the $\mathrm{Mn}$-center and promotes $\mathrm{O}-\mathrm{O}$ bond formation via a radical coupling reaction with a calculated reaction barrier of only $14.7 \mathrm{kcal} \mathrm{mol}^{-1}$. The $\mathrm{O}-\mathrm{O}$ bond formation step shares similarities with a mechanistic proposal for water oxidation by PSII
\end{abstract}




\section{Introduction}

Oxidizing water using solar energy to harvest electrons for the reduction of carbon dioxide into more useful commodity chemicals is a key technology for the abatement of our current dependence on fossil fuels and for reducing, if not eliminating the production of atmospheric greenhouse gases. ${ }^{1-4}$ Since the report of the "blue dimer", 5 one of the first homogeneous water oxidation catalysts, significant efforts have been made in developing water oxidation catalysts, ${ }^{6}$ particularly based on multiple metal centers inspired by the $\mathrm{Mn}_{4} \mathrm{CaO}_{5}$ cluster in the oxygen-evolving complex (OEC) of Photosystem II. ${ }^{7,8}$ Particularly interesting are catalysts based upon earth-abundant first-row transition metals, especially manganese, as it features in both the OEC and the active site of another oxygen-evolving enzyme, manganese catalase. ${ }^{9-11}$ The current limited understanding of the mechanism of $\mathrm{O}_{2}$ evolution in the $\mathrm{OEC}^{12-14}$ has slowed the development of synthetic Mn-based catalysts that mimic the mechanism of these natural systems. ${ }^{6,15}$ There have been a few reports of stoichiometric production of $\mathrm{O}_{2}$ from water or hydroxide using Mn-based systems. ${ }^{16,17}$ Catalytic $\mathrm{O}_{2}$ evolution ${ }^{18-23}$ can be achieved in the presence of water using chemical oxidants. ${ }^{24-29}$ Electrocatalytic $\mathrm{O}_{2}$ production has also been demonstrated typically in non-aqueous solvents. ${ }^{21,30,31}$ The robustness of these catalysts under standard reaction conditions often pose a significant challenge for identifying compounds that are truly molecular catalysts, rather than being precursors for nanoparticles or heterogeneous catalysts $<$ ref $15>$ that are active for $\mathrm{O}_{2}$ evolution.

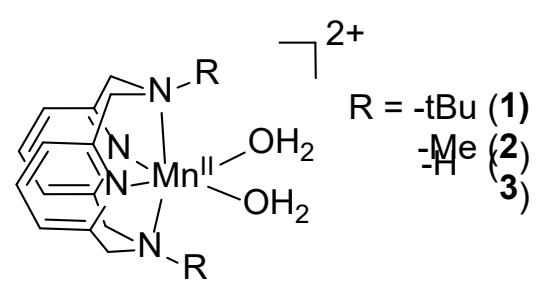

Figure 1. Structures of complexes 1, 2, and 3.

One of us recently reported a stable, homogeneous catalyst based on an pyridinophane macrocycle $\left[\mathrm{Mn}\left(\mathrm{Py}_{2} \mathrm{~N} t \mathrm{Bu}_{2}\right)\left(\mathrm{H}_{2} \mathrm{O}\right)_{2}\right]^{2+} \mathbf{1}$ for electrocatalytic water oxidation in aqueous solution at $\mathrm{pH}$ 12.2. ${ }^{32}$ Previous studies suggest that the catalyst is mononuclear and that switching the alkyl substituents from $\mathrm{Me}(2)$ or $\mathrm{H}(3)$ on the amino groups to tert-butyl changes the catalyst activity from hydrogen peroxide disproportionation to water oxidation. It was hypothesized that these large substituents prevent the formation of catalytically inactive manganese dimers. Mechanistic studies also showed that protontransfer from the aqua ligands accompanies complex oxidation, ${ }^{33}$ suggesting that the ligand framework can potentially support high-valent metal-oxo intermediates postulated to be responsible for forming the $\mathrm{O}-\mathrm{O}$ bond. Based on the first-order dependence of the rate on catalyst concentration and electrochemical 
studies, it was proposed that $\mathrm{O}-\mathrm{O}$ bond formation proceeded through nucleophilic attack of $\mathrm{H}_{2} \mathrm{O} / \mathrm{OH}^{-}$on a high-valent manganese oxo species. ${ }^{32}$

Understanding how this challenging reaction couples two oxygen atoms that are formally in a -II oxidation state is imperative for developing rational design strategies for improved catalysts. In the OEC, oxyl radical intermediates have been proposed to be necessary for $\mathrm{O}-\mathrm{O}$ bond formation. ${ }^{34-38}$ Similar electronic structures demonstrating redox non-innocence of the oxo fragment have been found for formally $\mathrm{Ru}^{\mathrm{V}}=\mathrm{O}$ fragment of the "blue dimer". ${ }^{39}$ Recently we have shown that a mononuclear Co-based catalyst is able to generate a biradicaloid oxene fragment with a formal oxidation state of zero that is remarkably reactive towards hydroxide in basic solution. This unusual electronic structure is facilitated by the accessibility of the high-spin state, which enables significant electron transfer from the oxo moiety into the half-filled $\mathrm{Co}-\mathrm{d} \pi$ orbitals of the highly electropositive metal center. ${ }^{40}$ Intrigued as to whether other first-row based catalysts possess other unusual electronic structures, or perhaps similar ones that are ultimately responsible for water oxidation, this work investigates how a single manganese ion supported by an aminopryidine macrocycle and featuring two oxygen-based ligands in a syn-configuration may facilitate $\mathrm{O}_{2}$ evolution.

\section{Computational Details}

All calculations were performed using density functional theory ${ }^{41,42}$ as implemented in the Jaguar 8.1 suite of ab initio quantum chemistry programs. ${ }^{43}$ Geometry optimizations were performed with the M06 functional using the $6-31 \mathrm{G}^{* *}$ basis set. ${ }^{44-48} \mathrm{Mn}$ was represented using the Los Alamos LACVP basis set that includes relativistic core potentials. ${ }^{49-51}$ More accurate single point energies were computed from the optimized geometries using Dunning's correlation-consistent triple- $\zeta$ basis set, cc-pVTZ(-f) that includes a double set of polarization functions. ${ }^{52} \mathrm{Mn}$ was represented using a modified version of LACVP, designated as LACV3P, in which the exponents were decontracted to match the effective core potential with triple- $\zeta$ quality. Vibrational frequencies were computed at the M06/6-31G** level of theory to derive zero point energy and vibrational entropy corrections from unscaled frequencies. Entropy here refers specifically to the vibrational/rotational/translational entropy of the solute(s), as the continuum model includes the entropy of the solvent. All intermediates were confirmed as local minima on the potential energy surface having zero imaginary frequencies. Transition states were confirmed to possess only one imaginary frequency. Solvation energies were evaluated using a selfconsistent reaction field (SCRF) approach based on accurate numerical solutions of the linearized Poisson-Boltzmann equation. ${ }^{53-56}$ Solvation calculations were carried out on the optimized gas-phase geometries using a dielectric constant of $\varepsilon=80.37$ for water and $\varepsilon=37.5$ for acetonitrile. As with all 
continuum models, the solvation energies are subject to empirical parameterization of the atomic radii that are used to generate the solute surface. We employ the standard set of optimized radii in Jaguar for $\mathrm{H}$ $(1.150 \AA), \mathrm{C}(1.900 \AA), \mathrm{N}(1.600 \AA), \mathrm{O}(1.600 \AA)$, and Mn (1.480 ̊). AF states were modeled using Noodleman's broken symmetry (BS) formalism without spin projection. ${ }^{57-59}$ The change in solution phase free energy $\Delta G($ sol) was calculated as follows:

$$
\begin{aligned}
& \Delta G(\text { sol })=\Delta G(\text { gas })+\Delta \Delta G_{\text {solv }} \\
& \Delta G(\text { gas })=\Delta H(\text { gas })-T \Delta S(\text { gas }) \\
& \Delta H(\text { gas })=\Delta E(\text { SCF })+\Delta Z P E
\end{aligned}
$$

$\Delta G$ (gas) is the change free energy in gas phase; $\Delta \Delta G_{\text {solv }}=$ change in free energy of solvation; $\Delta H($ gas $)=$ change in gas phase enthalpy; $T=$ temperature $(298.15 \mathrm{~K}) ; \Delta S($ gas $)=$ change in gas phase entropy; $\Delta E(\mathrm{SCF})=$ self-consistent field energy, i.e., "raw" electronic energy as computed from the SCF procedure at the triple- $\zeta$ level; $\triangle Z P E=$ change in vibrational zero point energy.

For computations involving proton-coupled redox reactions it is necessary to account for the free energy of a proton in solution. We used the following expression to compute $G\left(\mathrm{H}^{+}\right)$, the free energy of a proton in solution:

$$
G\left(\mathrm{H}^{+}\right)=H^{\text {gas }}\left(\mathrm{H}^{+}\right)-T S+\frac{5}{2} R T+G_{\text {solv }}\left(\mathrm{H}^{+}\right)
$$

where $H^{\text {gas }}\left(\mathrm{H}^{+}\right)$, the gas-phase electronic energy, is zero by definition; $R$ is the gas constant; $T$ is 298.15 $\mathrm{K} ; S$ is the translational entropy of a free hydrogen atom calculated using the Sackur-Tetrode equation (26.04 eu); $\frac{5}{2} R T$ is the thermal correction, which amounts to $0.064 \mathrm{eV}$ at $298.15 \mathrm{~K}$; and $G_{\text {solv }}\left(\mathrm{H}^{+}\right)$is the free energy of solvation of a proton $\left(-265.9 \mathrm{kcal} \mathrm{mol}^{-1}\right){ }^{60,61}$ Since experimental redox potentials are measured at $\mathrm{pH} 12.2$, our computed standard redox potentials were adjusted to the experimental $\mathrm{pH}$ conditions using the Nernst equation:

$$
E_{1 / 2}(\text { calcd })_{\mathrm{pH}}=E_{1 / 2}(\text { calcd })-R T \ln (10) / n_{e} \mathrm{x} n_{\mathrm{H}+} \mathrm{x} \mathrm{pH}
$$

where $n_{e}$ and $n_{\mathrm{H}^{+}}$are the numbers of electrons and protons, respectively. The value of $R T$ is computed to be $0.0257 \mathrm{~V}$ at $298.15 \mathrm{~K}$; thus, according to the above equation, $\sim 0.72 \mathrm{~V}$ should be subtracted from the computed standard redox potentials when one proton is involved in the redox reaction at $\mathrm{pH}$ 12.2. Reaction energies are calculated as follows: 


$$
\Delta \mathrm{G}(\mathrm{sol})_{\mathrm{rxn}}=\Delta \mathrm{G}(\mathrm{sol})_{\text {products }}-\Delta \mathrm{G}(\mathrm{sol})_{\text {reactants }}
$$

To account for the energy required to generate a hydroxide ion at $\mathrm{pH} 12.2$ an additional $0.72 \mathrm{~V}(16.6 \mathrm{kcal}$ $\mathrm{mol}^{-1}$ ) is added to the energies of any intermediates or transition states involving the direct addition of hydroxide (i.e. not through the stepwise addition of water). Coordinates of all calculated structures, vibrational frequencies, and calculated energy components are available in the online Supporting Information.

\section{Results and Discussion}

In order for our computational analysis to properly select intermediates that are most relevant for the water oxidation mechanism, it is important to benchmark our calculations against experimental observables. The complex was crystallographically characterized as the acetonitrile solvate $\left[\mathrm{Mn}^{\mathrm{II}}\left(\mathrm{Py}_{2} \mathrm{~N} t \mathrm{Bu}_{2}\right)(\mathrm{ACN})_{2}\right]^{2+} 4 .^{32}$ The ground state of this $\mathrm{Mn}(\mathrm{II})-\mathrm{d}^{5}$ complex 4 is calculated to be the highspin (HS) sextet state, which is $37.1 \mathrm{kcal} \mathrm{mol}^{-1}$ lower in energy than the low-spin (LS) alternative, quartet state. Figure 2 shows the optimized structure of the sextet complex ${ }^{6} 4$ and the most pertinent bond lengths and angles are compared to those of the previously reported X-Ray crystal structure in Table 1. The structural parameters of the DFT optimized structure are in good agreement with those found in the crystal structure with most of the computed bond lengths being slightly longer than the experimental values. It is well established that density functional calculations tend to yield slightly expanded structures with overestimated bond lengths in transition metal complexes. ${ }^{62}$

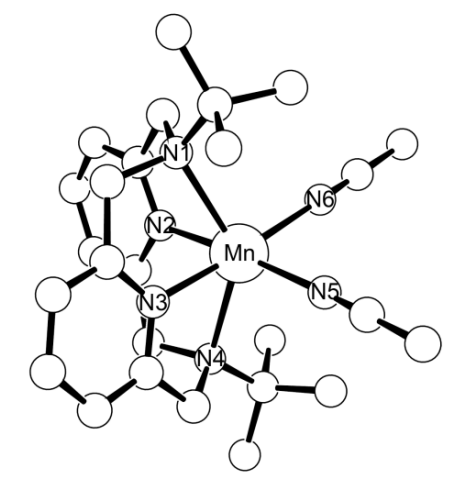

Figure 2. Optimized structure of ${ }^{6} 4$. Hydrogen atoms are omitted for clarity.

The geometry of ${ }^{\mathbf{6}} \mathbf{4}$ provides a useful benchmark for modeling the $\mathrm{Mn}^{\mathrm{II}}$ high-spin (HS) resting state for the catalytic cycle. But a key question is what the nature of the intermediate responsible for $\mathrm{O}-\mathrm{O}$ bond formation may be: is it formally a $\mathrm{Mn}^{\mathrm{IV}}=\mathrm{O}$ or a $\mathrm{Mn}^{\mathrm{V}}=\mathrm{O}$ species? Both have been proposed to be 
relevant for water oxidation. ${ }^{8,34-38,63,64}$ Because these high-valent oxo intermediates are highly reactive, they are often fleeting intermediates during catalysis making them difficult to study experimentally. Previously, we showed that redox potentials for transition metal complexes can be successfully approximated using density functional calculations ${ }^{65}$ and theoretical models of protoncoupled electron transfer reactions are well established. ${ }^{66,67}$ Thus, our quantum chemical models constitute a reasonable platform for investigating which reactive species should predominate in solution following electrochemical oxidation. The cyclic voltammogram of $\left[\mathrm{Mn}^{\mathrm{II}}\left(\mathrm{Py}_{2} \mathrm{~N} t \mathrm{Bu}_{2}\right)\left(\mathrm{H}_{2} \mathrm{O}\right)_{2}\right]^{2+} \mathbf{1}$ at $\mathrm{pH}$ 12.2 in aqueous solution displays a Faradaic response at ca. $1.0 \mathrm{~V}$ along with a large irreversible wave that has an onset potential of approximately $1.3 \mathrm{~V}$ and a peak potential at about $1.5 \mathrm{~V} .{ }^{32}$ Because our calculations produce normal potentials, they should not match these experimental peak potentials. ${ }^{68}$ But the experimental peak potential can be expected to serve as an upper limit for the normal potentials calculated assuming different redox-active species.

Table 1. Select bond lengths in $\AA$ and angles in ${ }^{\circ}$ for crystal and optimized structures of ${ }^{6} 4$.

\begin{tabular}{ccc}
\hline & Experimental $^{32}$ & Computed \\
\hline Mn-N1 & 2.455 & 2.460 \\
Mn-N2 & 2.165 & 2.172 \\
Mn-N3 & 2.236 & 2.167 \\
Mn-N4 & 2.415 & 2.467 \\
Mn-N5 & 2.152 & 2.303 \\
Mn-N6 & 2.211 & 2.303 \\
N1-Mn-N4 & 143.4 & 137.4 \\
\hline
\end{tabular}

Scheme 1 illustrates the relative energies of postulated electrochemical intermediates that may be formed en route to generating a high-valent metal-oxo species at $\mathrm{pH}$ 12.2. The removal of electrons is shown with vertical arrows as the associated normal potential vs. NHE for each oxidation process. Deprotonation energies are visualized in the horizontal direction. The calculated $\mathrm{pK}_{\mathrm{a}}$ value for each intermediate is listed in red on top of the horizontal arrow with the corresponding pH-adjusted Gibbs free energy for the deprotonation event given below the arrow in black. The diagonal arrows then correlate with the removal of both a proton and electron in concert as a proton-coupled electron transfer (PCET) event. For the initial $\mathrm{Mn}^{\mathrm{II}}$ complex $\mathbf{1}$, the sextet state ${ }^{6} \mathbf{1}$ is favored over the quartet by $46.0 \mathrm{kcal}$ $\mathrm{mol}^{-1}$. The $\mathrm{pK}_{\mathrm{a}}$ of one of the aqua protons on ${ }^{6} \mathbf{1}$ is calculated to be 11.35 , which at $\mathrm{pH} 12.2$ suggests that 
the equilibrium between ${ }^{6} \mathbf{1}$ and ${ }^{6} \mathbf{5}$ should slightly favor the latter with ${ }^{6} \mathbf{5}$ being $1.2 \mathrm{kcal} \mathrm{mol}^{-1}$ more favorable in terms of $\Delta \mathrm{G}(\mathrm{sol})$.

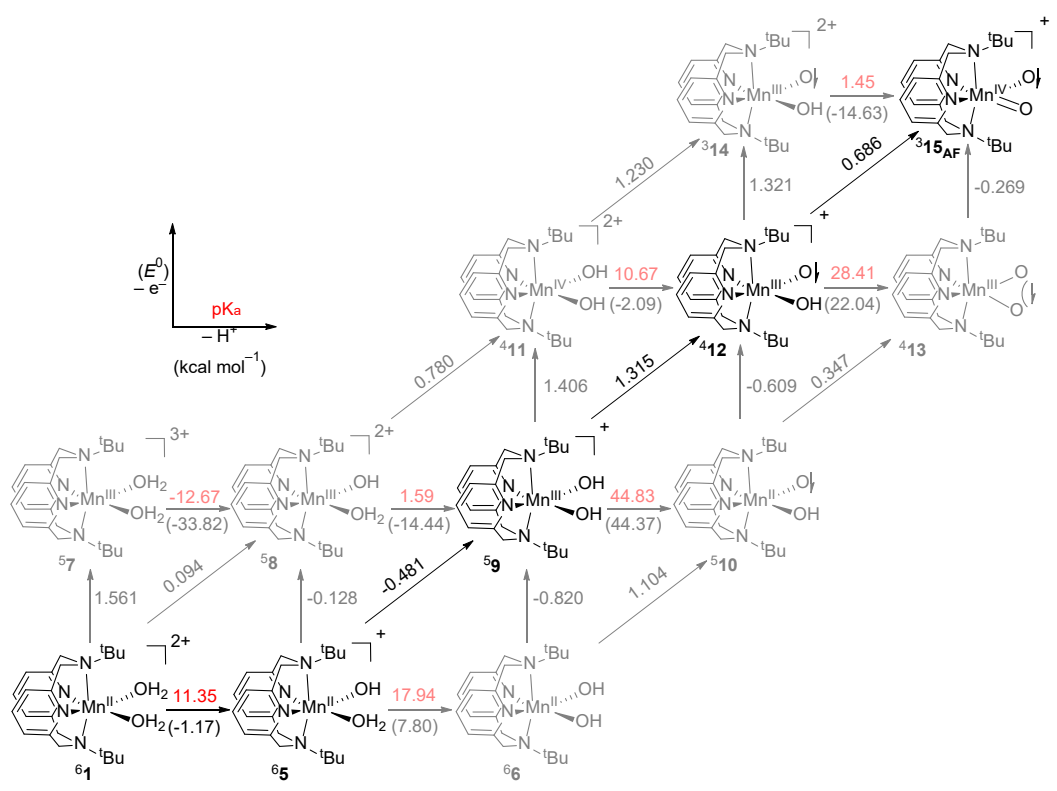

Scheme 1. Relative energies of potential electrochemical intermediates.

Oxidation of the dicationic ${ }^{6} \mathbf{1}$ requires $1.561 \mathrm{~V}$ vs. NHE, but removal of an electron from ${ }^{6} \mathbf{5}$ needs only $-0.128 \mathrm{~V}$ vs. NHE as the initial removal of a proton allows for avoiding excessive charge buildup around the metal center. The resulting $\mathrm{Mn}^{\mathrm{III}}$ ion in ${ }^{5} \mathbf{8}$ adopts a HS configuration, as the quintet state is favored over the triplet state by $33.0 \mathrm{kcal} \mathrm{mol}{ }^{-1}$. Our calculations indicate, that ${ }^{5} \mathbf{8}$ will rapidly deprotonate and generate the $\mathrm{Mn}^{\mathrm{III}}$-bis(hydroxyl) species ${ }^{5} \mathbf{9}$ given the calculated $\mathrm{pK}_{\mathrm{a}}$ of 1.59 - therefore, we do not expect ${ }^{5} \mathbf{8}$ to be detectable experimentally, as illustrated in grey in Scheme 1. The ease of deprotonation of ${ }^{5} \mathbf{8}$ indicates that the removal of the electron and proton should occur in a concerted fashion as a PCET, which is calculated to have an overall normal potential of $-0.481 \mathrm{~V}$ vs. NHE. The alternative $\left[\mathrm{Mn}^{\mathrm{III}}\left(\mathrm{Py}_{2} \mathrm{~N} t \mathrm{Bu}_{2}\right)(\mathrm{O})\left(\mathrm{OH}_{2}\right)\right]^{+}$complex ${ }^{5} \mathbf{9 A}$ was also examined, but the quintet state for this isomer was found to be $37.2 \mathrm{kcal} \mathrm{mol}^{-1}$ higher in energy than ${ }^{5} \mathbf{9}$, disqualifying it from being relevant.

Removal of a proton from ${ }^{5} 9$ is prohibitively high in energy, requiring $44.4 \mathrm{kcal} \mathrm{mol}^{-1}$. The removal of a single electron to give ${ }^{4} \mathbf{1 1}$ is calculated to require $1.406 \mathrm{~V}$ vs. NHE, whereas coupling the removal of the electron with a proton should proceed at a more negative potential of $1.315 \mathrm{~V}$ vs. NHE to produce ${ }^{4} \mathbf{1 2}$. The bis(hydroxyl) species ${ }^{4} \mathbf{1 1}$ is $6.8 \mathrm{kcal} \mathrm{mol}^{-1}$ lower in energy than the $\left[\mathrm{Mn}^{\mathrm{IV}}\left(\mathrm{Py}_{2} \mathrm{~N} t \mathrm{Bu}_{2}\right)(\mathrm{O})\left(\mathrm{OH}_{2}\right)\right]^{2+}$ intermediate ${ }^{4} \mathbf{1 1 A}$. Species ${ }^{4} \mathbf{1 2}$ contains formally a $\left[\mathrm{Mn}^{\mathrm{IV}}=\mathrm{O}\right]^{+}$fragment, the electronic structure of which can be better described using the resonance form $\left[\mathrm{Mn}^{\mathrm{III}}-\mathrm{O} \cdot\right]^{+}$based on Mulliken spin density analysis that assigns an excess $\alpha$-spin density of 3.60 on $\mathrm{Mn}$ and excess $\beta$-spin 
density of 0.71 on the oxo moiety. This spin distribution is most consistent with a HS $\mathrm{Mn}^{\mathrm{III}}$ ion that is antiferromagnetically (AF) coupled to an oxyl radical ligand. The sextet ${ }^{6} \mathbf{1 2}$ featuring a HS $\mathrm{Mn}^{\mathrm{III}}$ center (Mulliken spin density of $3.90 \alpha$ ) and an oxyl radical fragment with a parallel Mulliken spin population $1.01 \alpha$ was found to be $15.5 \mathrm{kcal} \mathrm{mol}^{-1}$ above the quartet state. The doublet state was located at an even higher $22.0 \mathrm{kcal} \mathrm{mol}^{-1}$ above the ground state quartet. Our calculations indicate that an additional PCET from ${ }^{4} 12$ to yield ${ }^{3} \mathbf{1 5}_{\mathrm{AF}}$ should occur at a potential of just $0.686 \mathrm{~V}$ vs. NHE. As this second potential is more negative than the preceding PCET event, this should result in potential inversion associated with a single two-electron event where the observed redox potential the average of the two single-electron redox potentials. ${ }^{69-72}$ For the two proton/two electron coupled transfer event from ${ }^{5} \mathbf{9}$ to ${ }^{3} \mathbf{1 5}_{\mathrm{AF}}$, this two-electron event is calculated to be observable at $1.000 \mathrm{~V}$ vs. NHE. However, as the experimental redox events in aqueous solution are irreversible they cannot be directly correlated to our calculated results. Nonetheless, our calculations predict that the formally $\mathrm{Mn}^{\mathrm{V}}$-bis(oxo) intermediate ${ }^{3} \mathbf{1 5}_{\mathrm{AF}}$ is the most likely candidate to be responsible for $\mathrm{O}-\mathrm{O}$ bond formation following the electrochemical oxidation.

Table 2. Most plausible electronic configurations of $\mathbf{1 5 .}$

\begin{tabular}{|c|c|c|c|c|c|c|}
\hline & ${ }^{5} 15$ & ${ }^{5} 15_{\mathrm{AF}}$ & ${ }^{3} 15$ & ${ }^{3} 15_{\mathrm{AF}}$ & ${ }^{1} 15$ & ${ }^{1} \mathbf{1 5}_{\mathrm{AF}}$ \\
\hline$\Delta \mathrm{G}\left(\mathrm{kcal} \mathrm{mol}^{-1}\right)$ & 9.06 & 12.84 & 4.28 & 0.00 & 28.13 & 18.37 \\
\hline Spin density (Mn) & $2.26 \alpha$ & $3.49 \alpha$ & $1.82 \alpha$ & $2.36 \alpha$ & $0.30 \beta$ & $0.02 \beta$ \\
\hline Spin density (O1) & $0.90 \alpha$ & $1.09 \alpha$ & $0.11 \alpha$ & $0.52 \beta$ & $0.24 \alpha$ & $0.53 \beta$ \\
\hline Spin density (O2) & $0.90 \alpha$ & $0.62 \beta$ & $0.15 \alpha$ & $0.06 \alpha$ & $0.06 \alpha$ & $0.55 \alpha$ \\
\hline $\mathrm{Mn}-\mathrm{O} 1(\AA)$ & 1.701 & 1.818 & 1.615 & 1.620 & 1.587 & 1.611 \\
\hline $\mathrm{Mn}-\mathrm{O} 2(\AA)$ & 1.701 & 1.696 & 1.616 & 1.591 & 1.580 & 1.612 \\
\hline Mn ox. state (spin state) ${ }^{\mathrm{a}}$ & +III (IS) & +III (HS) & $+\mathrm{V}(\mathrm{HS})$ & +IV (HS) & +V (LS) & +III (LS) \\
\hline
\end{tabular}

${ }^{\text {a }}$ IS: intermediate spin state; HS: high-spin state; LS: low-spin state

The electronic structure of intermediate $\mathbf{1 5}$ is complicated and we identified six different electronic configurations that are plausible and must be considered. The relative energies of these different electronic arrangements along with diagnostic Mulliken spin densities of the manganese and oxygen atoms, the manganese-oxygen bond lengths, and the oxidation state of the manganese ion with a designation of high spin, intermediate spin, or low spin are given in Table 2.

The ground state, denoted as ${ }^{3} \mathbf{1 5}_{\mathrm{AF}}$, exhibits AF coupling between one of the oxygen atoms (O1), which has an excess $\beta$-spin density of 0.52 , and the Mn-center that has an $\alpha$-spin population of 2.36 . The 
other oxygen atom $\mathrm{O} 2$ has a slightly shorter Mn-O bond length of $1.591 \AA$ compared to $1.620 \AA$ and only a small amount of residual spin density of 0.06 , suggesting that this oxygen is appropriately described as a classical oxo moiety. It should be noted that the spin density of 0.52 on O1, while suggestive, does not necessarily indicate an oxyl radical, ${ }^{33,73}$ as it is possible that the $\mathrm{Mn}^{\mathrm{V}}=\mathrm{O}$ bond is highly covalent in nature and the excess spin density on the oxo fragment is a result of strong $\pi$-donation from one of the singly occupied $\mathrm{d}-\pi$ orbitals of the high-spin Mn center. Realistically, the electronic structure of the $\mathrm{Mn}^{\mathrm{V}}=\mathrm{O}$ fragment is best described as a superposition of the two extremes. The oxygen in similar electronic structure patterns have previously been interpreted as being oxyl radicals, as this interpretation provides a convenient rationale for the observed water oxidation reactivity. ${ }^{34,37,39,63,74-76}$ An alternative triplet configuration where the metal center has not been reduced by the $\mathrm{O} 1$ and retains its $+\mathrm{V}$ oxidation state ${ }^{3} \mathbf{1 5}$ is $4.3 \mathrm{kcal} \mathrm{mol}{ }^{-1}$ higher in energy than ${ }^{3} \mathbf{1 5}_{\mathrm{AF}}$. Two singlet states were found, one of which shows AF coupling between oxyl radicals on each of the oxygen atoms, but these spin configurations are significantly higher in energy by 28.1 and $18.4 \mathrm{kcal} \mathrm{mol}^{-1}$ than the triplet ground state and can be safely discarded.

a)
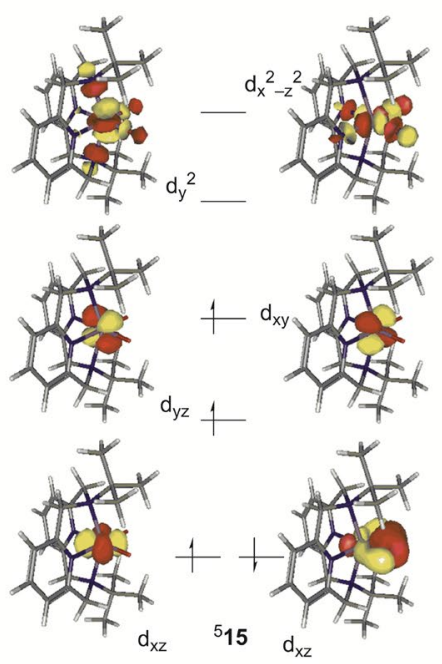

b)
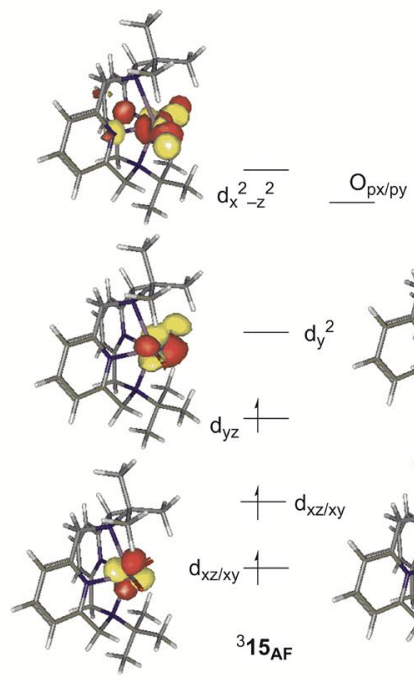
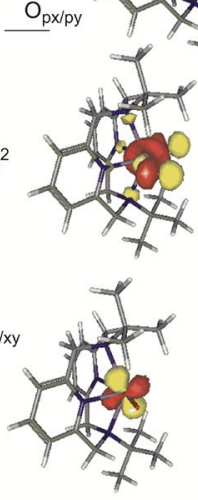

c)
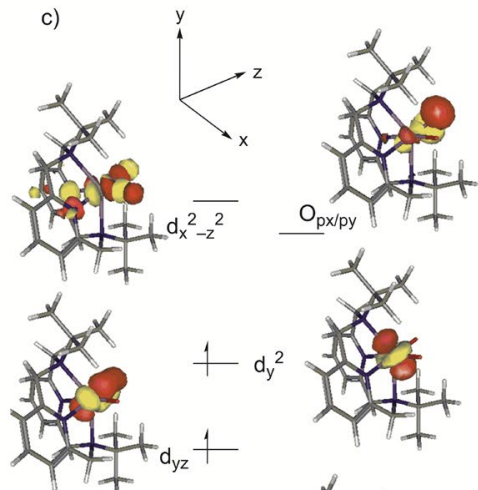

Figure 3. Electronic structures of a) ${ }^{5} \mathbf{1 5}$, b) ${ }^{3} \mathbf{1 5}_{\mathrm{AF}}$, and c) ${ }^{5} \mathbf{1 5}_{\mathrm{AF}}$

The quintet spin surface also provides two potential spin configurations that both lie higher in energy than ${ }^{3} \mathbf{1 5}_{\mathrm{AF}}$, but are low enough to be thermally populated at room temperature. The lowest energy of these configurations ${ }^{5} \mathbf{1 5}$ is $9.1 \mathrm{kcal} \mathrm{mol}^{-1}$ above ${ }^{3} \mathbf{1 5}_{\mathrm{AF}}$ and has an electronic structure most consistent with an intermediate-spin $\mathrm{Mn}^{\mathrm{III}}$. With a Mulliken spin density of $2.26 \alpha$, the unpaired electrons on the metal are coupled ferromagnetically to the electrons of the oxyl radicals on each of the oxygen atoms. The lengthening of each of the $\mathrm{Mn}-\mathrm{O}$ bonds to $1.701 \AA$ is consistent with electron transfer from 
the metal-oxo $\pi$-bonding orbital. Located slightly higher in energy at $12.8 \mathrm{kcal} \mathrm{mol}^{-1}$ relative to ${ }^{3} \mathbf{1 5}_{\mathrm{AF}}$ the other potential quintet configuration ${ }^{5} \mathbf{1 5}_{\mathrm{AF}}$ possess strong AF coupling between the two oxygen atoms having spin densities of $1.09 \alpha$ and $0.62 \beta$, respectively. The $\mathrm{Mn}-\mathrm{O} 1$ bond distance is considerably lengthened to a distance of $1.818 \AA$ compared to the Mn-oxyl bond lengths of $1.701 \AA$ in ${ }^{5} \mathbf{1 5}$. The exceptionally long bond length along with the particularly high spin density of $1.09 \alpha$ on $\mathrm{O} 1$ hints at a significant extent of electron transfer between and $\mathrm{O} 1$ and Mn suggesting that some oxene character, i.e. oxygen in a formally zero oxidation state, is present. Such a highly oxidized oxygen moiety is expected to be an exceptionally strong oxidant and provide an intuitively understandable explanation for the remarkable oxidative reactivity of the $\mathrm{Mn}$ complex. The spin density on $\mathrm{Mn}$ of 3.49 is intermediate between HS $\mathrm{Mn}^{\mathrm{III}}$ and IS $\mathrm{Mn}^{\mathrm{II}}$. The occupations of the metal-based orbitals localized using the Boys localization scheme, however, support the assignment of a HS $\mathrm{Mn}^{\mathrm{III}}$ ion as shown in Figure 3. The high oxidation state of the formally $\mathrm{Mn}^{\mathrm{V}}$ center results in an inversion of the classical metal-oxo bonding picture, where the $\mathrm{Mn}-\mathrm{O} \pi$ orbital is significantly polarized towards the metal and the $\mathrm{Mn}-\mathrm{O} \pi$ * orbital is largely oxo-based. ${ }^{73,77}$

The mechanism generally accepted for $\mathrm{O}-\mathrm{O}$ bond formation in mononuclear water oxidation catalysts involves nucleophilic attack of water or hydroxide on a high-valent metal-oxo fragment. ${ }^{78,79}$ Radical coupling mechanisms between oxyl radicals on two discrete metal sites have also been proposed, ${ }^{24,80,81}$ but the first-order kinetics on catalyst concentration in the current case precludes such a bimolecular pathway. We have extensively sampled the potential energy surface for all plausible spin states and probed several reasonable reaction pathways, illustrated in Figure 4 for $\mathrm{O}-\mathrm{O}$ bond formation step.

Despite exhaustive efforts, we were unable to locate any transition state originating directly from the resting state ${ }^{\mathbf{3}} \mathbf{1 5}_{\mathbf{A F}}$ to afford a reaction barrier that is consistent with a room temperature reaction (vide infra). Interestingly, we found that the quintet species ${ }^{\mathbf{5}} \mathbf{1 5} \mathbf{A F}$ is a much better candidate for promoting the $\mathrm{O}-\mathrm{O}$ coupling. The transition state that leads to a $\eta^{2}$-bound peroxo intermediate ${ }^{\mathbf{5}} \mathbf{1 6}$ is only $1.8 \mathrm{kcal} / \mathrm{mol}$ higher than ${ }^{\mathbf{5}} \mathbf{1 5}_{\mathrm{AF}}$. This reaction trajectory invokes an intersystem crossing (ISC) from the triplet surface where the resting state ${ }^{3} \mathbf{1 5}_{\mathbf{A F}}$ is located to the quintet surface to access the low energy transition state $\mathbf{5}_{\mathbf{1 5}}$-TS. The resulting reaction barrier is reasonable at $14.7 \mathrm{kcal} / \mathrm{mol}$, but the intersystem crossing is intrinsically coupled to a significant change in electronic structure in addition to the spin state transition. As highlighted by differing formal oxidation states of the Mn-center in ${ }^{\mathbf{3}} \mathbf{1 5}_{\mathrm{AF}}$ and ${ }^{\mathbf{5}} \mathbf{1 5}_{\mathrm{AF}}$, the electronic configurations found in these two complexes cannot be reached by a simple spin flip and requires electron density to be transferred between one of the ligands and the metal center. Formal reduction of the $\mathrm{Mn}(\mathrm{IV})$ center in ${ }^{\mathbf{3}} \mathbf{1 5} \mathrm{AF}$ to $\mathrm{Mn}(\mathrm{III})$ in ${ }^{\mathbf{5}} \mathbf{1 5} \mathrm{AF}$ utilizes one of the lone-pair electrons of the oxo moiety. Following the electron transfer, the two oxyl fragments in ${ }^{\mathbf{5}} \mathbf{5}_{\mathbf{A F}}$ with spin densities of $1.09 \alpha$ and $0.62 \beta$, 
respectively, can combine in a radical coupling reaction to form the peroxo intermediate. The Mulliken spin densities enumerated in Table 2 and the simplified Lewis structures shown in Figure 4 illustrate this process.

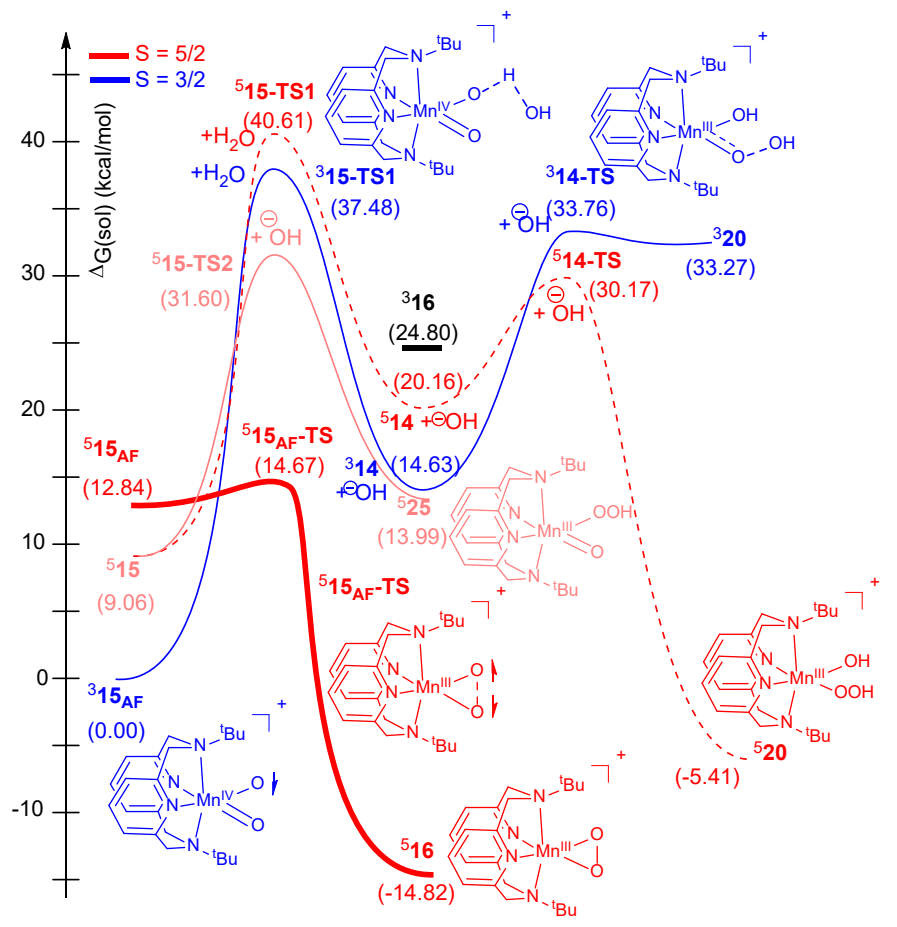

Figure 4. Energy profile for the formation of the $\mathrm{O}-\mathrm{O}$ bond.
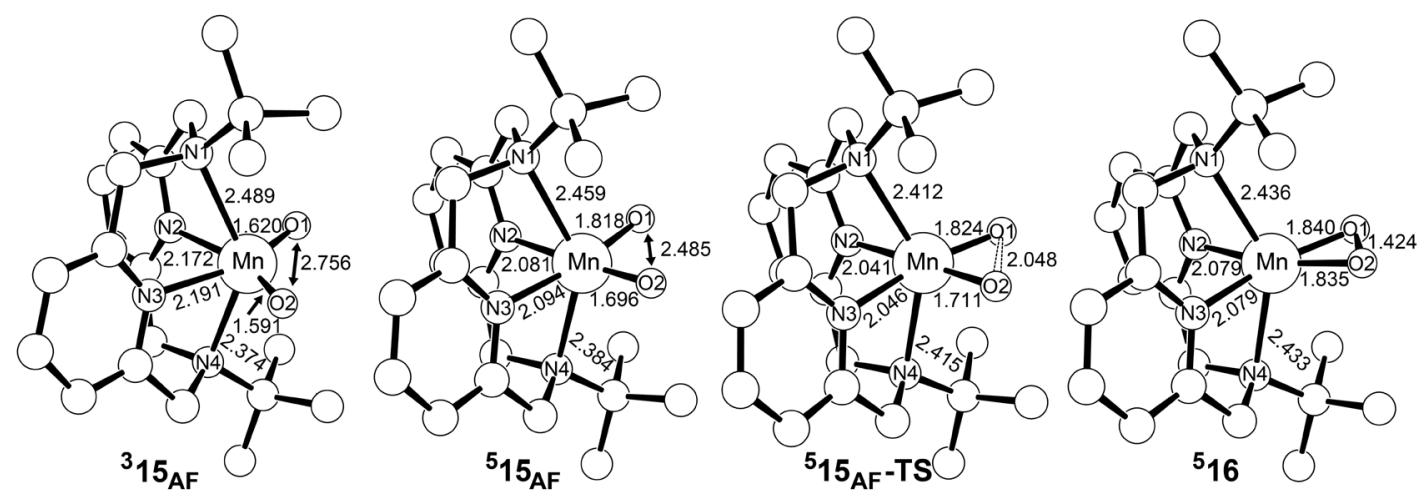

Figure 5. Optimized structures of intermediates during $\mathrm{O}-\mathrm{O}$ bond formation.

The intersystem crossing from the triplet to the quintet potential energy surface is likely to be challenging to accomplish due to the significant structural change that accompanies the spin crossover. Both of the equatorial Mn-N bonds contract by about $0.1 \AA$ and the N2-Mn-N3 angle expands from $76^{\circ}$ to $84^{\circ}$. Both $\mathrm{Mn}-\mathrm{O}$ bonds lengthen considerably as the $\mathrm{Mn}-\mathrm{O} 1$ bond length increases by $0.198 \AA$ and the 
$\mathrm{Mn}-\mathrm{O} 2$ bond length by $0.105 \AA$. The $\mathrm{O} 1-\mathrm{Mn}-\mathrm{O} 2$ angle also shrinks considerably from $118^{\circ}$ in ${ }^{\mathbf{3}} \mathbf{1 5}_{\mathrm{AF}}$ to just $90^{\circ}$ in ${ }^{\mathbf{5}} \mathbf{1 5}_{\mathbf{A F}}$. The two oxygen atoms are drawn into a much closer proximity as a result with the $\mathrm{O}-\mathrm{O}$ distance contracting from $2.756 \AA$ to $2.485 \AA$ priming the complex for the $\mathrm{O}-\mathrm{O}$ coupling reaction. The structure of ${ }^{\mathbf{5}_{15}} \mathbf{5}_{\mathrm{AF}}$ is very similar to that found at the transition state ${ }^{\mathbf{5}} \mathbf{1 5}_{\mathrm{AF}}-\mathbf{T S}$ and the resulting product 516, where the only major structural difference is the continued contraction of the $\mathrm{O}-\mathrm{O}$ distance. Thus, it enables an extremely facile radical coupling reaction between the two oxyl radical fragments of ${ }^{\mathbf{5}} \mathbf{1 5}_{\mathbf{A F}}$ once it is formed despite the penalty in reaction rate incurred for the intersystem crossing.

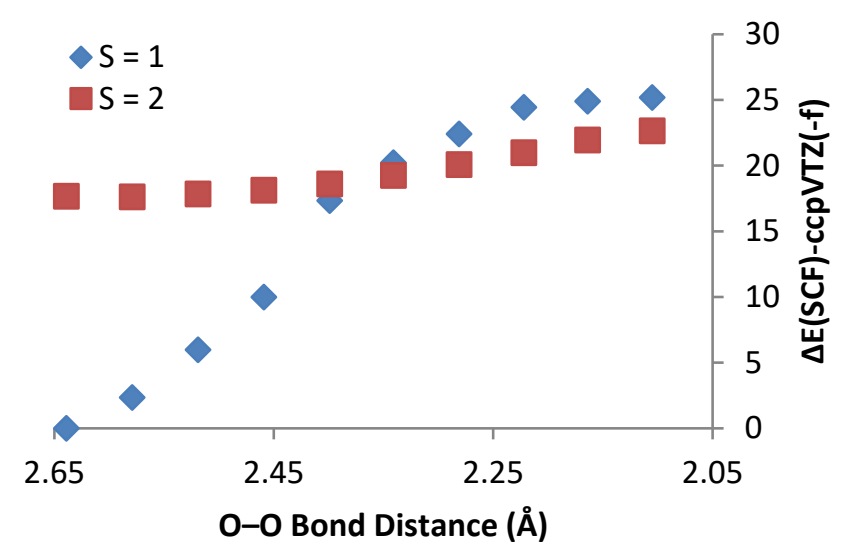

Figure 6. Relative electronic energies of triplet and quintet states in a scan between the geometries of ${ }^{3} 15_{\mathrm{AF}}$ and ${ }^{5} 15_{\mathrm{AF}}-\mathrm{TS}$.

To estimate the energetic cost for reaching the intersystem crossing point on the potential energy surface, we performed a linear synchronous transit scan between the geometries of the reactant structure ${ }^{3} \mathbf{1 5}_{\mathrm{AF}}$ and the transition state ${ }^{\mathbf{5}} \mathbf{1 5}_{\mathrm{AF}}$-TS. From the data in Figure 6 it is clear that on the electronic potential energy surface that the triplet state is favored until the $\mathrm{O}-\mathrm{O}$ bond distance contracts to about $2.34 \AA$. At this point the electronic energy penalty is about $17 \mathrm{kcal} \mathrm{mol}^{-1}$ relative to the energy of the reactant. However, factors such as entropy and solvation reduce this overall penalty to only $14.7 \mathrm{kcal}$ $\mathrm{mol}^{-1}$ at the transition state.

Considering a nucleophilic attack of the $\mathrm{Mn}-\mathrm{O}$ moiety by water in either a concerted asynchronous fashion, we were unable to locate a transition state for the concerted addition of water to intermediate 15. A concerted mechanism is unlikely as each of the otherwise symmetry equivalent oxo fragments would be required to behave differently: one would need to act as a Brønstead base in order to abstract a proton from water, whereas the other oxo moiety would have to function as a Lewis acid towards the incipient hydroxide ion. The calculated barrier to proton transfer to one of the oxo fragments ${ }^{3} \mathbf{1 5}$-TS1 is calculated to be $37.5 \mathrm{kcal} \mathrm{mol}^{-1}$ on the triplet surface and $40.6 \mathrm{kcal} \mathrm{mol}^{-1}$ through ${ }^{5} \mathbf{1 5}-\mathbf{T S} 1$ on the quintet surface. Subsequent attack of the resulting hydroxide molecule on the remaining oxo group is 
indicated by our calculations to be most favorable for the quintet state ${ }^{5} \mathbf{1 4}-\mathbf{T S}$ with a barrier of $30.2 \mathrm{kcal}$ $\mathrm{mol}^{-1}$. The transition state for addition of hydroxide on the triplet surface ${ }^{3} \mathbf{1 4}$-TS was found at $33.8 \mathrm{kcal}$ $\mathrm{mol}^{-1}$. The high barrier to protonation, however, suggests that this pathway should not be viable under ambient conditions. Considering that the hydroxyl proton on ${ }^{3} \mathbf{1 4}$ has a calculated $\mathrm{pK}_{\mathrm{a}}$ of 1.45 , which

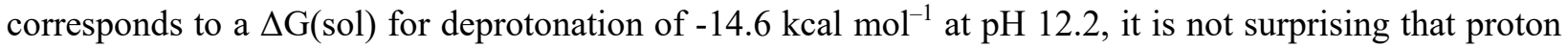
transfer is a prohibitively difficult step. The adduct structures where the hydroxide ion formed after proton transfer to intermediate $\mathbf{1 5}$ remains hydrogen bonded to species $\mathbf{1 4}$ are less stable than the structures lacking this interaction at 27.5 and $28.2 \mathrm{kcal} \mathrm{mol}^{-1}$ higher in energy than ${ }^{3} \mathbf{1 5}_{\mathrm{AF}}$ on the triplet and quintet surfaces, respectively. We have also calculated the barrier for directly adding hydroxide to the bis(oxo) intermediate, which occurs on the quintet surface with a barrier of just $15.0 \mathrm{kcal} \mathrm{mol}^{-}$ 1. However, there is a significant thermodynamic penalty for generating a hydroxide ion from water in aqueous solution, which at $\mathrm{pH} 12.2$ is approximately $16.6 \mathrm{kcal} \mathrm{mol}^{-1}$ rendering the overall barrier for the addition of hydroxide via ${ }^{5} \mathbf{1 5}$-TS2 to be $31.6 \mathrm{kcal} \mathrm{mol}^{-1}$.

The presence in ${ }^{3} \mathbf{1 5}_{\mathrm{AF}}$ of two oxygen-based ligands in a cis position relative to one another in addition to the fact that the oxyl radicals are AF coupled invited the intriguing proposition of an intramolecular coupling between radical fragments to generate a $\mathrm{Mn}^{\mathrm{III}}$-peroxo intermediate. Despite the weakly coupled AF triplet ${ }^{3} \mathbf{1 5}_{\mathrm{AF}}$ being the ground state for the formally $\mathrm{Mn}^{\mathrm{V}}$-bis(oxo) intermediate, the intramolecular coupling occurs most favorably on the quintet surface through ${ }^{5} \mathbf{1 5}_{\mathbf{A F}}$-TS with a barrier of just $14.7 \mathrm{kcal} \mathrm{mol}^{-1}$. This is not surprising as the resulting $\mathrm{Mn}^{\mathrm{III}}$-peroxo ${ }^{5} \mathbf{1 6}$ is more stable on the quintet surface by $38.8 \mathrm{kcal} \mathrm{mol}^{-1}$ relative to the triplet surface. The septet ${ }^{7} \mathbf{1 6}$ is the second lowest spin state for the peroxo intermediate and is $13.3 \mathrm{kcal} \mathrm{mol}^{-1}$ higher in energy than the quintet. The formation of ${ }^{5} \mathbf{1 6}$ is downhill thermodynamically from ${ }^{3} \mathbf{1 5}_{\mathrm{AF}}$ by $14.0 \mathrm{kcal} \mathrm{mol}^{-1}$. This two-state reactivity ${ }^{82}$ enabled by the accessible high-spin states provided by the first-row transition metal center facilitates a relatively low barrier for $\mathrm{O}-\mathrm{O}$ bond formation. The intramolecular coupling on the quintet surface is, of course, facilitated by the AF coupling between the two oxyl radicals exhibited in ${ }^{5} \mathbf{1 5}_{\mathrm{AF}}$ rather than the electronic structure in ${ }^{5} \mathbf{1 5}$ featuring parallel $\alpha$-spins on the oxyl moieties.

This proposed mechanism for $\mathrm{O}-\mathrm{O}$ bond formation in a mononuclear catalyst is unusual. Proposals for intramolecular coupling mechanisms for $\mathrm{O}-\mathrm{O}$ bond formation on mononuclear catalysts are rare and confined to $\mathrm{H}_{2} \mathrm{O}_{2}$ generation, ${ }^{83,84}$ whereas direct ${ }^{3} \mathrm{O}_{2}$ production is generally limited to dinuclear catalysts. $^{85-88}$ We note that intramolecular $\mathrm{O}-\mathrm{O}$ bond formation has been proposed during the photodecomposition of $\mathrm{MnO}_{4}{ }^{-89,90}$ although this reaction only occurs under photochemical conditions.

At the transition state, the structure of which is shown in Figure 5, the $\mathrm{Mn}-\mathrm{O}$ bond lengths are only increased to $1.824 \AA$ and $1.711 \AA$ from $1.818 \AA$ and $1.696 \AA$ in $\mathbf{5}_{\mathbf{A F F}}$, respectively. The $\mathrm{O}-\mathrm{O}$ bond distance has decreased significantly to $2.048 \AA$ from $2.464 \AA$ and the O1-Mn-O2 angle decreases from 
$138.6^{\circ}$ to $70.7^{\circ}$. The Mulliken spin density on $\mathrm{O} 1$ decreases from 1.01 to 0.93 and increases on $\mathrm{O} 2$ from 0.56 to -0.64 along with a decrease on $\mathrm{Mn}$ from 3.63 to 3.42 .

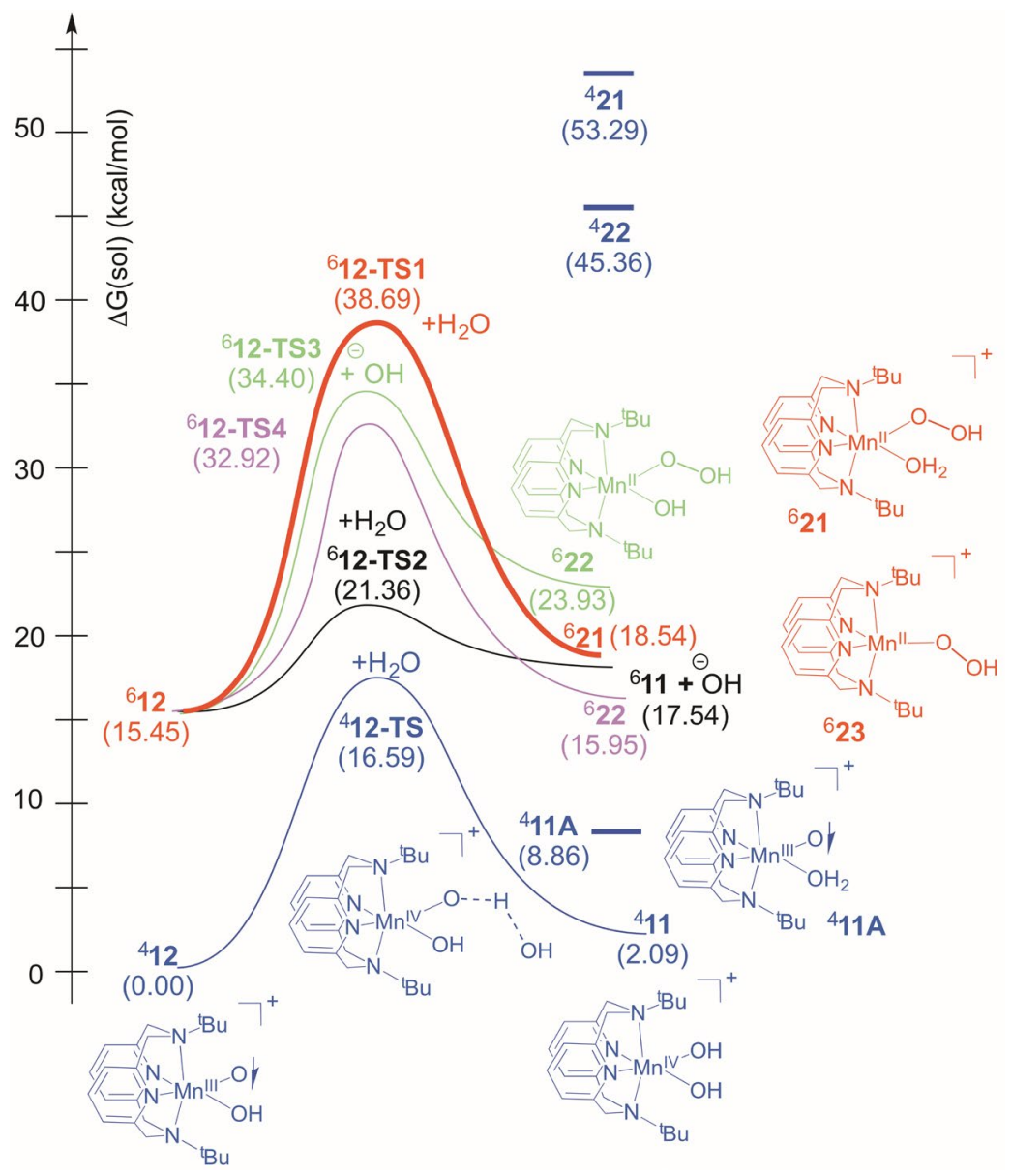

Figure 7. Energetic profile for $\mathrm{O}-\mathrm{O}$ bond formation at the formal $\mathrm{Mn}^{\mathrm{IV}}$ oxidation state.

To determine whether it is necessary to access the formal $\mathrm{Mn}^{\mathrm{V}}$ oxidation state to facilitate $\mathrm{O}-\mathrm{O}$ bond formation, or whether the $\mathrm{Mn}^{\mathrm{IV}}$-intermediate ${ }^{4} \mathbf{1 2}$ could form the $\mathrm{O}-\mathrm{O}$ bond, we examined several mechanistic scenarios starting from the $\left[\mathrm{Mn}^{\mathrm{IV}}(=\mathrm{O})(\mathrm{OH})\right]^{+}$intermediate ${ }^{4} \mathbf{1 2}$, as shown in Figure 7. The electronic structure of this species may be best described from the Mulliken spin density on the oxo fragment of -0.706 as $\left[\mathrm{Mn}^{\mathrm{III}}(\mathrm{O} \bullet)(\mathrm{OH})\right]^{+}$, where an oxyl radical is AF coupled to a high-spin $\mathrm{Mn}^{\mathrm{III}}$ ion. Based on our calculated electrochemical potentials we do not expect this species to persist in solution as the calculated potential to access the formally $\mathrm{Mn}^{\mathrm{V}}$-bis(oxo) ${ }^{3} \mathbf{1 5}$ is more negative than the potential to produce ${ }^{4} \mathbf{1 2}$, which should result in potential inversion where the observed electrochemical event should occur as a single two-electron response. ${ }^{69-72,94}$ Nevertheless, to ensure that the ${ }^{4} \mathbf{1 2}$ is not responsible for $\mathrm{O}-\mathrm{O}$ bond formation we have modeled several different plausible pathways described below. 
In ${ }^{6} 12$ the asymmetry of the oxygen-ligands with one being an oxyl and the other a hydroxyl fragment enables significant radical character on the oxyl fragment. As a result, the transfer of a proton from water to the hydroxyl ligand of ${ }^{6} \mathbf{1 2}$ occurs in a concerted fashion with nucleophilic attack of the incipient hydroxide molecule on the oxyl ligand. The concerted addition of water occurs with a barrier of $38.7 \mathrm{kcal} \mathrm{mol}^{-1}$ on the sextet potential energy surface shown in bold red line in Figure 7 producing ${ }^{6} \mathbf{2 1}$. On the quartet surface, shown in blue in Figure 7, the resulting product ${ }^{4} \mathbf{2 1}$ is $53.3 \mathrm{kcal} \mathrm{mol}^{-1}$ higher in energy than the reactant ${ }^{4} \mathbf{1 2}$ making the addition of water not feasible for this spin state. The high energy barrier calculated for this process is not surprising as it requires proton transfer to the less basic hydroxyl fragment relative to the oxo moiety. Transition states for the transfer of a proton from water to the oxyl radical fragment of intermediate 12 were found with barriers of 16.6 and $21.4 \mathrm{kcal} \mathrm{mol}^{-1}$ on the quartet and sextet surfaces traversing the transition states ${ }^{4} \mathbf{1 2}-\mathbf{T S}$ and ${ }^{6} \mathbf{1 2}-\mathbf{T S 2}$, respectively. The hydroxyl protons on the water addition product ${ }^{4} \mathbf{1 1}$ have a calculated $\mathrm{pK}_{\mathrm{a}}$ of 10.7 , which suggests that this intermediate should readily deprotonate under experimental conditions. Moreover, the bis(hydroxyl) intermediate is not be expected to be active for $\mathrm{O}-\mathrm{O}$ bond formation. Protonation of the hydroxyl ligand of ${ }^{4} \mathbf{1 2}$ rather than the more basic oxo fragment in ${ }^{4} \mathbf{1 1} \mathbf{A}$ is thermodynamically uphill by $8.9 \mathrm{kcal} \mathrm{mol}^{-1}$ and the expected kinetic barrier to proton transfer should also be more difficult to overcome. Attempts to find the transition states for the asynchronous proton transfer to the hydroxyl ligand instead were unsuccessful. The barrier for the subsequent addition of hydroxide is expected to be more difficult for ${ }^{4} \mathbf{1 1 A}$ compared to ${ }^{3} \mathbf{1 4}$ as the less oxidizing $\mathrm{Mn}^{\mathrm{III}}$ center of ${ }^{4} \mathbf{1 1 A}$ will not render the bound oxo moiety as nucleophilic as the $\mathrm{Mn}^{\mathrm{IV}}$ center of ${ }^{3} \mathbf{1 4}$. Therefore, even if proton transfer is possible to ${ }^{4} \mathbf{1 1 A}$, the following addition of hydroxide should be more difficult than the $30.2 \mathrm{kcal} \mathrm{mol}^{-1}$ calculated for ${ }^{5} \mathbf{1 4}$-TS.

The direct addition of hydroxide to intermediate ${ }^{4} \mathbf{1 2}$ results in an intermediate ${ }^{4} \mathbf{2 2}$ that is 45.4 $\mathrm{kcal} \mathrm{mol}^{-1}$ above ${ }^{4} \mathbf{1 2}$. Such hydroxide addition is more favorable on the sextet surface through ${ }^{6} \mathbf{1 2}-\mathbf{T S 3}$, depicted in green in Figure 7, with a barrier of $34.4 \mathrm{kcal} \mathrm{mol}^{-1}$, but this is still too high to be viable under ambient conditions. An intramolecular coupling, shown in magenta color in Figure 7, between the hydroxyl fragment and the oxo group furnishing ${ }^{6} \mathbf{2 3}$ was explored and is also more favorable on the sextet surface with a barrier via ${ }^{6} \mathbf{1 2}$-TS4 of $32.9 \mathrm{kcal} \mathrm{mol}^{-1}$, which is again not a meaning reaction trajectory under experimental conditions. All these calculations suggest that oxidation of water is not possible at the $\mathrm{Mn}^{\mathrm{IV}}$ oxidation state and that further oxidation to $\mathrm{Mn}^{\mathrm{V}}$ is necessary.

The complete mechanism for catalytic water oxidation is summarized in Figure 8. The aforementioned discussion covered the most difficult and complicated portion up to the formation of the $\mathrm{Mn}^{\mathrm{III}}$-peroxo intermediate ${ }^{5} \mathbf{1 6}$. To complete the catalytic cycle, one additional electron must be removed. Addition of a water molecule to ${ }^{5} \mathbf{1 6}$ prior to oxidation is uphill by $5.9 \mathrm{kcal} \mathrm{mol}^{-1}$. The oxidation occurs with a calculated potential of $1.169 \mathrm{~V}$ vs. NHE and the electron is removed from the 
peroxo ligand in ${ }^{4} \mathbf{1 7}$ rather than the $\mathrm{Mn}$ as the spin density on $\mathrm{Mn}$ increases from 4.111 to 4.223. The calculated potential of $1.169 \mathrm{~V}$ is close to the approximate onset potential for catalysis at ca. $1.3 \mathrm{~V}$. The amount of $\beta$-spin density increases from -0.101 and -0.097 to -0.672 and -0.693 on each of the oxygen atoms, respectively. The sextet ${ }^{6} \mathbf{1 7}$, where the superoxyl fragment is ferromagnetically coupled to the Mn-center, is $6.2 \mathrm{kcal} \mathrm{mol}^{-1}$ higher in energy than the energetically more favorable antiferromagnetically coupled alternative ${ }^{4} \mathbf{1 7}$. Intramolecular transfer of an electron from the superoxyl moiety in ${ }^{4} \mathbf{1 7}$ to $\mathrm{Mn}$ produces a HS $\mathrm{Mn}^{\mathrm{II}}$ ion AF coupled to triplet dioxygen. Release of ${ }^{3} \mathrm{O}_{2}$ takes place with a calculated barrier of $7.5 \mathrm{kcal} \mathrm{mol}^{-1}$ and is thermodynamically favorable by $1.5 \mathrm{kcal} \mathrm{mol}^{-1}$. Complexation of two molecules of water to the resulting four coordinate intermediate ${ }^{6} \mathbf{1 8}$ regenerates ${ }^{6} \mathbf{1}$ and is downhill by $12.3 \mathrm{kcal} \mathrm{mol}^{-1}$ to complete the catalytic cycle.

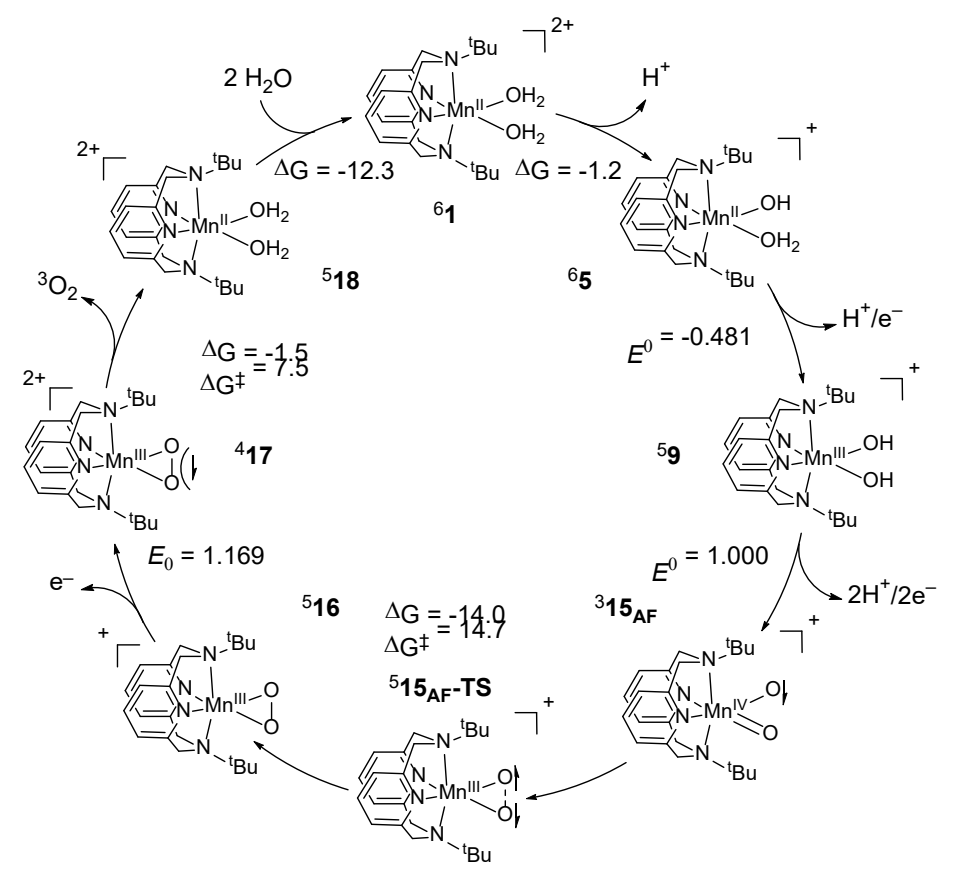

Figure 8. Proposed catalytic cycle for water oxidation. 


\section{Conclusions}

In summary, our calculations have demonstrated that the oxidation of water by $\left[\mathrm{Mn}\left(\mathrm{Py}_{2} \mathrm{~N} t \mathrm{Bu}_{2}\right)\left(\mathrm{H}_{2} \mathrm{O}\right)_{2}\right]^{2+}$ should proceed through a $\mathrm{Mn}^{\mathrm{V}}$-bis(oxo) intermediate that is accessed by a series of proton-coupled electron transfer events. The second of these redox events is calculated to be the concerted removal of two electrons along with two protons at an inverted potential. That is, the second PCET is more favorable than the first. The ground state of the $\mathrm{Mn}^{\mathrm{V}}$-bis(oxo) species is the triplet state, but our calculations suggest that a thermally accessible quintet state displaying AF coupling between two oxyl radical fragments facilitates $\mathrm{O}-\mathrm{O}$ bond formation with a calculated barrier of just $14.7 \mathrm{kcal} \mathrm{mol}^{-1}$. Through the understanding gained by elucidating the electronic structure of the catalytically competent intermediate is possible to understand how two terminal aqua ligands may be coupled to form a peroxide intermediate. Further oxidation of the resulting $\mathrm{Mn}^{\mathrm{III}}$-peroxo species gives a $\mathrm{Mn}^{\mathrm{III}}$-superoxyl intermediate that can transfer an electron from the superoxyl moiety to Mn to release triplet dioxygen and regenerate the initial $\mathrm{Mn}^{\mathrm{II}}$ state. This work furthers our understanding of how the accessible high-spin states available for first-row transition metal ions enhance the oxidative reactivity of homogeneous water oxidation catalysts.

Our results also provide insight into the critical role played by the pyridinophane ligand in facilitating catalytic water oxidation. In addition to providing the appropriate electronic environment for accessing multiple oxidation and spin states, the geometry and flexibility of this ligand is critical to $\mathrm{O}-\mathrm{O}$ bond formation. Specifically, in addition to creating the cis-divacant octahedral environment required for the intramolecular $\mathrm{O}-\mathrm{O}$ bond coupling event, the flexibility of the ligand in traversing a range of N2-Mn$\mathrm{N} 3$ bond angles promotes efficient $\mathrm{O}-\mathrm{O}$ coupling with a low energy barrier.

Finally, we note that our proposed $\mathrm{O}-\mathrm{O}$ coupling mechanism shares similarities with $\mathrm{O}-\mathrm{O}$ bond formation proposals that involve the coupling of two terminal aqua ligands in PSII. ${ }^{14}$ While the currently favored mechanism for $\mathrm{O}_{2}$ evolution involves bond formation in the center of the OEC between an oxyl radical and a bridging oxo ligand, an alternative proposal involves the coupling of two terminal water molecules bound to the dangling manganese ion of the tetramanganese cluster. ${ }^{93}$ Such a pathway can avoid the potentially high energy barrier to O-O formation using a bridging oxo. . $2,14,38,91,92$ Importantly, although our mechanism does not provide insight into the roles played by the rest of the OEC cluster, it does show that intramolecular $\mathrm{O}-\mathrm{O}$ coupling at a single manganese ion is thermally accessible, and it can occur with a barrier that is similar to that observed for PSII.

\section{Acknowledgements}

We thank the Institute for Basic Science (IBS-R10-D1) in Korea, the ACS-PRF (50971-ND3 to JMS) and the Research Corporation (Scialog Award to MHB) for support. 


\section{Synopsis TOC}

The mechanism of water oxidation by a manganese pyridinophane catalyst has been investigated by computational methods. The key O-O bond forming step occurs by an intramolecular oxyl radical coupling reaction, with $\Delta G^{\ddagger}=14.7 \mathrm{kcal} \mathrm{mol}^{-1}$

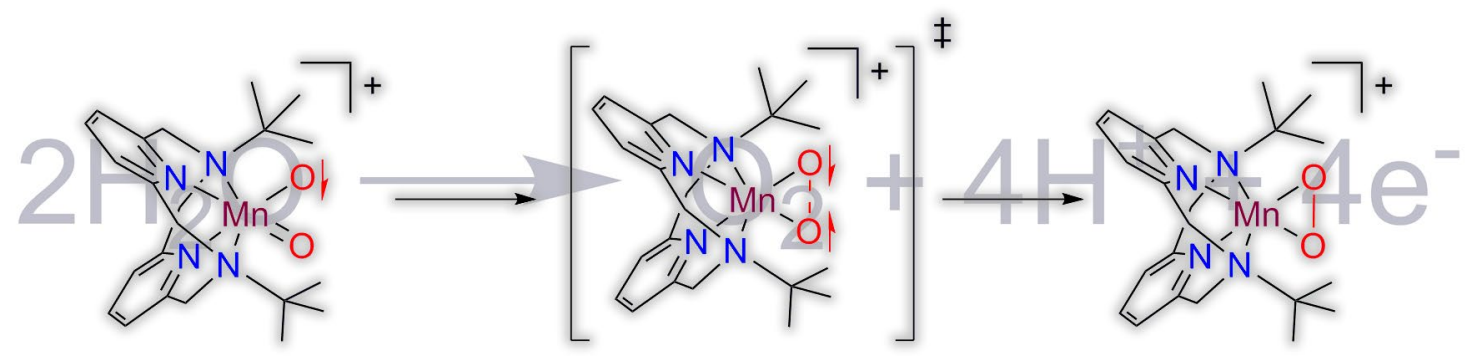




\section{REFERENCES}

(1) Lewis, N. S.; Nocera, D. G. Proc. Natl. Acad. Sci. U. S. A. 2006, 103, 15729-15735.

(2) Lewis, N. S.; Nocera, D. G. Proc. Natl. Acad. Sci. U. S. A. 2007, 104, 20142.

(3) Alstrum-Acevedo, J. H.; Brennaman, M. K.; Meyer, T. J. Inorg. Chem. 2005, 44, 6802-

6827.

(4) Gust, D.; Moore, T. A.; Moore, A. L. Acc. Chem. Res. 2001, 34, 40-48.

(5) Gilbert, J. A.; Eggleston, D. S.; Murphy, W. R.; Geselowitz, D. A.; Gersten, S. W.; Hodgson, D. J.; Meyer, T. J. J. Am. Chem. Soc. 1985, 107, 3855-3864.

(6) Liu, X.; Wang, F. Coord. Chem. Rev. 2012, 256, 1115-1136.

(7) Umena, Y.; Kawakami, K.; Shen, J.-R.; Kamiya, N. Nature 2011, 473, 55-60.

(8) McEvoy, J. P.; Brudvig, G. W. Chem. Rev. 2006, 106, 4455-4483.

(9) Wu, A. J.; Penner-Hahn, J. E.; Pecoraro, V. L. Chem. Rev. 2004, 104, 903-938.

(10) Antonyuk, S. V.; Melik-Adamyan, V. R.; Popov, A. N.; Lamzin, V. S.; Hempstead, P. D.;

Harrison, P. M.; Artymyuk, P. J.; Barynin, V. V. Crystallogr. Rep. 2000, 45, 105-116.

(11) Barynin, V. V.; Whittaker, M. M.; Antonyuk, S. V.; Lamzin, V. S.; Harrison, P. M.;

Artymiuk, P. J.; Whittaker, J. W. Structure 2001, 9, 725-738.

(12) Siegbahn, P. E. M. Acc. Chem. Res. 2009, 42, 1871-1880.

(13) Yamanaka, S.; Isobe, H.; Kanda, K.; Saito, T.; Umena, Y.; Kawakami, K.; Shen, J. R.;

Kamiya, N.; Okumura, M.; Nakamura, H.; Yamaguchi, K. Chem. Phys. Lett. 2011, 511, 138-145.

(14) Shen, J.-R. Annu. Rev. Plant Biol. 2015, 66, 23-48.

(15) Artero, V.; Fontecave, M. Chem. Soc. Rev. 2013, 42, 2338-2356.

(16) Shimazaki, Y.; Nagano, T.; Takesue, H.; Ye, B.-H.; Tani, F.; Naruta, Y. Angew. Chem. Int.

Ed. 2004, 43, 98-100.

(17) Gao, Y.; Åkermark, T.; Liu, J.; Sun, L.; Åkermark, B. J. Am. Chem. Soc. 2009, 131, 8726-

8727.

(18) Cady, C. W.; Crabtree, R. H.; Brudvig, G. W. Coord. Chem. Rev. 2008, 252, 444-455.

(19) Wiechen, M.; Berends, H.-M.; Kurz, P. Dalton Trans. 2012, 41, 21-31.

(20) Karlsson, E. A.; Lee, B.-L.; Åkermark, T.; Johnston, E. V.; Kärkäs, M. D.; Sun, J.; Hansson,

Ö.; Bäckvall, J.-E.; Åkermark, B. Angew. Chem. Int. Ed. 2011, 50, 11715-11718.

(21) Gao, Y.; Crabtree, R. H.; Brudvig, G. W. Inorg. Chem. 2012, 51, 4043-4050.

(22) Seidler-Egdal, R. K.; Nielsen, A.; Bond, A. D.; Bjerrum, M. J.; McKenzie, C. J. Dalton Trans. 2011, 40, 3849-3858.

(23) Young, K. J.; Takase, M. K.; Brudvig, G. W. Inorg. Chem. 2013, 52, 7615-7622.

(24) Yoshida, M.; Masaoka, S.; Abe, J.; Sakai, K. Chem. Asian J. 2010, 5, 2369-2378.

(25) Chen, H.; Tagore, R.; Olack, G.; Vrettos, J. S.; Weng, T.-C.; Penner-Hahn, J.; Crabtree, R.

H.; Brudvig, G. W. Inorg. Chem. 2007, 46, 34-43.

(26) Wasylenko, D. J.; Ganesamoorthy, C.; Henderson, M. A.; Koivisto, B. D.; Osthoff, H. D.; Berlinguette, C. P. J. Am. Chem. Soc. 2010, 132, 16094-16106.

(27) Wasylenko, D. J.; Ganesamoorthy, C.; Henderson, M. A.; Berlinguette, C. P. Inorg. Chem. 2011, 50, 3662-3672.

(28) Parent, A. R.; Crabtree, R. H.; Brudvig, G. W. Chem. Soc. Rev. 2013, 42, 2247-2252.

(29) Hetterscheid, D. G. H.; Reek, J. N. H. Eur. J. Inorg. Chem. 2014, 2014, 742-749.

(30) Gao, Y.; Liu, J.; Wang, M.; Na, Y.; Åkermark, B.; Sun, L. Tetrahedron 2007, 63, 1987-1994.

(31) Naruta, Y.; Sasayama, M.; Sasaki, T. Angew. Chem. Int. Ed. Engl. 1994, 33, 1839-1841. 
(32) Lee, W.-T.; Muñoz, S. B.; Dickie, D. A.; Smith, J. M. Angew. Chem. Int. Ed. 2014, 53, 9856-

9859.

(33) Lassalle-Kaiser, B.; Hureau, C.; Pantazis, D. A.; Pushkar, Y.; Guillot, R.; Yachandra, V. K.; Yano, J.; Neese, F.; Anxolabehere-Mallart, E. Energy Environ. Sci. 2010, 3, 924-938.

(34) Siegbahn, P. E. M. Chem. Eur. J. 2006, 12, 9217-9227.

(35) Messinger, J. Phys. Chem. Chem. Phys. 2004, 6, 4764-4771.

(36) Liang, W.; Roelofs, T. A.; Cinco, R. M.; Rompel, A.; Latimer, M. J.; Yu, W. O.; Sauer, K.;

Klein, M. P.; Yachandra, V. K. J. Am. Chem. Soc. 2000, 122, 3399-3412.

(37) Siegbahn, P. E. M. Inorg. Chem. 2000, 39, 2923-2935.

(38) Siegbahn, P. E. M. Chem. Eur. J. 2008, 14, 8290-8302.

(39) Yang, X.; Baik, M.-H. J. Am. Chem. Soc. 2004, 126, 13222-13223.

(40) Crandell, D. W.; Ghosh, S.; Berlinguette, C. P.; Baik, M.-H. ChemSusChem 2015, 8, 844-

852.

(41) Parr, R. G.; Yang, W. Density Functional Theory of Atoms and Molecules; Oxford University Press: New York, 1989.

(42) Ziegler, T. Chem. Rev. 1991, 91, 651-667.

(43) Jaguar 8.1; Schrödinger, Inc., New York, NY, 2014.

(44) Zhao, Y.; Truhlar, D. Theor. Chem. Acc. 2008, 120, 215-241.

(45) Slater, J. C. Quantum Theory of Molecules and Solids, Vol. 4: The Self-Consistent Field for Molecules and Solids; McGraw-Hill: New York, 1974.

(46) Vosko, S. H.; Wilk, L.; Nusair, M. Can. J. Phys. 1980, 58, 1200-1211.

(47) Petersson, G. A.; Bennett, A.; Tensfeldt, T. G.; Al-Laham, M. A.; Shirley, W. A.; Mantzaris, J. J. Chem. Phys. 1988, 89, 2193-2218.

(48) Petersson, G. A.; Al-Laham, M. A. J. Chem. Phys. 1991, 94, 6081-6090.

(49) Hay, P. J.; Wadt, W. R. J. Chem. Phys. 1985, 82, 270-283.

(50) Wadt, W. R.; Hay, P. J. J. Chem. Phys. 1985, 82, 284-298.

(51) Hay, P. J.; Wadt, W. R. J. Chem. Phys. 1985, 82, 299-310.

(52) Dunning, T. H., Jr. J. Chem. Phys. 1989, 90, 1007-1023.

(53) Marten, B.; Kim, K.; Cortis, C.; Friesner, R. A.; Murphy, R. B.; Ringnalda, M. N.; Sitkoff, D.; Honig, B. J. Phys. Chem. 1996, 100, 11775-11788.

(54) Friedrichs, M.; Zhou, R. H.; Edinger, S. R.; Friesner, R. A. J. Phys. Chem. B 1999, 103, 3057-3061.

(55) Edinger, S. R.; Cortis, C.; Shenkin, P. S.; Friesner, R. A. J. Phys. Chem. B 1997, 101, 11901197.

(56) Rashin, A. A.; Honig, B. J. Phys. Chem. 1985, 89, 5588-5593.

(57) Noodleman, L.; Lovell, T.; Han, W.-G.; Li, J.; Himo, F. Chem. Rev. 2004, 104, 459-508.

(58) Noodleman, L. J. Chem. Phys. 1981, 74, 5737-5743.

(59) Noodleman, L.; Davidson, E. R. Chem. Phys. 1986, 109, 131-143.

(60) Tissandier, M. D.; Cowen, K. A.; Feng, W. Y.; Gundlach, E.; Cohen, M. H.; Earhart, A. D.; Coe, J. V.; Tuttle, T. R., Jr. J. Phys. Chem. A 1998, 102, 7787-7794.

(61) Kelly, C. P.; Cramer, C. J.; Truhlar, D. G. J. Phys. Chem. B 2006, 110, 16066-16081.

(62) Minenkov, Y.; Singstad, A.; Occhipinti, G.; Jensen, V. R. Dalton Trans. 2012, 41, 5526-

5541.

(63) Siegbahn, P. E. M.; Crabtree, R. H. J. Am. Chem. Soc. 1999, 121, 117-127.

(64) Messinger, J.; Badger, M.; Wydrzynski, T. Proc. Natl. Acad. Sci. U. S. A. 1995, 92, 3209-

3213.

(65) Baik, M.-H.; Friesner, R. A. J. Phys. Chem. A 2002, 106, 7407-7412. 
(66) Hammes-Schiffer, S.; lordanova, N. Biochimica et Biophysica Acta (BBA) - Bioenergetics 2004, 1655, 29-36.

(67) Solis, B. H.; Hammes-Schiffer, S. Inorg. Chem. 2014, 53, 6427-6443.

(68) McCormick, M. C.; Keijzer, K.; Polavarapu, A.; Schultz, F. A.; Baik, M.-H. J. Am. Chem. Soc. 2014, 136, 8992-9000.

(69) Lord, R. L.; Schauer, C. K.; Schultz, F. A.; Baik, M.-H. J. Am. Chem. Soc. 2011, 133, 18234-

18242.

(70) Evans, D. H. Chem. Rev. 2008, 108, 2113-2144.

(71) Evans, D. H.; Hu, K. J. Chem. Soc., Faraday Trans. 1996, 92, 3983-3990.

(72) Evans, D. H. Acta Chem. Scand. 1998, 52, 194-197.

(73) Sameera, W. M. C.; McGrady, J. E. Dalton Trans. 2008, 6141-6149.

(74) Lundberg, M.; Blomberg, M. R. A.; Siegbahn, P. E. M. Inorg. Chem. 2004, 43, 264-274.

(75) Yang, X.; Baik, M.-H. J. Am. Chem. Soc. 2006, 128, 7476-7485.

(76) Lundberg, M.; Siegbahn, P. E. M. Phys. Chem. Chem. Phys. 2004, 6, 4772-4780.

(77) Gebhard, M. S.; Koch, S. A.; Millar, M.; Devlin, F. J.; Stephens, P. J.; Solomon, E. I. J. Am. Chem. Soc. 1991, 113, 1640-1649.

(78) Betley, T. A.; Wu, Q.; Van Voorhis, T.; Nocera, D. G. Inorg. Chem. 2008, 47, 1849-1861.

(79) Cao, R.; Lai, W.; Du, P. Energy Environ. Sci. 2012, 5, 8134-8157.

(80) Nyhlén, J.; Duan, L.; Åkermark, B.; Sun, L.; Privalov, T. Angew. Chem. Int. Ed. 2010, 49, 1773-1777.

(81) Duan, L.; Bozoglian, F.; Mandal, S.; Stewart, B.; Privalov, T.; Llobet, A.; Sun, L. Nat Chem 2012, 4, 418-423.

(82) Schröder, D.; Shaik, S.; Schwarz, H. Acc. Chem. Res. 2000, 33, 139-145.

(83) Kohl, S. W.; Weiner, L.; Schwartsburd, L.; Konstantinovski, L.; Shimon, L. J. W.; BenDavid, Y.; Iron, M. A.; Milstein, D. Science 2009, 324, 74-77.

(84) Yang, X.; Hall, M. B. J. Am. Chem. Soc. 2010, 132, 120-130.

(85) Yang, X.; Baik, M.-H. J. Am. Chem. Soc. 2008, 130, 16231-16240.

(86) Ghosh, S.; Baik, M.-H. Angew. Chem. Int. Ed. 2012, 51, 1221-1224.

(87) Bozoglian, F.; Romain, S.; Ertem, M. Z.; Todorova, T. K.; Sens, C.; Mola, J.; Rodríguez, M.; Romero, I.; Benet-Buchholz, J.; Fontrodona, X.; Cramer, C. J.; Gagliardi, L.; Llobet, A. J. Am. Chem. Soc. 2009, 131, 15176-15187.

(88) Wada, T.; Ohtsu, H.; Tanaka, K. Chem. Eur. J. 2012, 18, 2374-2381.

(89) Lee, D. G.; Moylan, C. R.; Hayashi, T.; Brauman, J. I. J. Am. Chem. Soc. 1987, 109, 3003-

3010.

(90) Thornley, W. A.; Bitterwolf, T. E. Inorg. Chem. 2015, 54, 3370-3375.

(91) Rapatskiy, L.; Cox, N.; Savitsky, A.; Ames, W. M.; Sander, J.; Nowaczyk, M. M.; Rögner, M.; Boussac, A.; Neese, F.; Messinger, J.; Lubitz, W. J. Am. Chem. Soc. 2012, 134, 16619-16634.

(92) Pérez Navarro, M.; Ames, W. M.; Nilsson, H.; Lohmiller, T.; Pantazis, D. A.; Rapatskiy, L.; Nowaczyk, M. M.; Neese, F.; Boussac, A.; Messinger, J.; Lubitz, W.; Cox, N. Proc. Natl. Acad. Sci. 2013, 110, 15561-15566.

(93) Kusunoki, M. J. Photochem. Photobiol., B 2011, 104, 100-110.

(94) Evans, D. H. Acta Chem. Scand. 1999, 53, 765-774. 